\title{
The Analysis of the Beauty and Characteristics of Tibetan Folk Songs in Nanping Sichuan
}

\author{
Juanjuan Cheng \\ School of Music, China West Normal University, Nanchong, 637000, China
}

Keywords: Tibetan folk songs; style; musical scale; singing

\begin{abstract}
In the vast western Sichuan with rich Tibetan culture, there is Kangba cultural centre, the heaven of folk songs and dance, with splendid culture with long history. This essay sets Tibetan folk songs in Nanping as example to explore the beauty and characteristics and analyze the culture, characteristics, style and form in this ancient land which are different from that in other regions.
\end{abstract}

\section{Introduction}

Nanping in Sichuan is the Jiuzhaigou county today in which there is a large number of Tibetan people and rich Tibetan culture. The people there belong to Baima Tibetan and the singing and dancing, customs and culture there are different from that of Tibetan in other regions. In terms of folk songs, it is famous for Heishui qu and Pipa playing. It deserves to be the people of singing and dancing. This essay will briefly introduce the types of Tibetan folk songs in Nanping such as enveloped song, Heishui and wedding songs, etc. Then this essay will state in details the beauty and characteristics of Tibetan folk songs in Nanping from musical scales to other aspects like mode, the core columns, features of turning methods and singing.

\section{The types of Tibetan folk songs in Nanping Sichuan}

Before the scenic area Jiuzhaihou was developed, Nanping was famous for Pipa playing and rewarded as "the town of folk songs" and "the town of Pipa". "Pipa playing” is a kind of rap art, playing and singing by Han people in Nanping. People like playing in festive holidays especially in Spring Festival. It is the folk traditional art of which most are oral literature except a few fixed singing ways. From this point of Tibetan culture in this region, where there is Tibetan history, there is Tibetan language and words, there is folk song. The Tibetan culture is always close connected with its surrounding cultures. And the Tibetan culture has its own characteristics because of inconvenient transportation and long-term close. There is more An duo culture and Kangba culture in Tibetan in Shang tang and there is more Baima culture in Xia tang. However, Nanping which is located in the middle of Shang tang and Xia tang is the synthesis of An duo, Kangba and Baima culture. Regarding as the detailed types of folk songs, the Tibetan folk songs in Nanping includes legendary songs, antiphonal songs, bless songs, Heishui qu and enveloped songs, etc.

The content of legendary songs is the form, the shape and the functions of natural things. Toast songs are sung in important holidays and the greeting parties when toasting and they are ended with "God blesses you". Bless songs include wedding songs, songs for new houses, wishing songs and worship god songs. Heishui qu is common in Nanping and it concentrates singing and dancing and is play by many people in a cycle. Heishui qu can be divided to Zhenda Heishui, Muya Heishui, Danba Heishui, Mani Heishui and Jiubu Heishui. Heishui qu in Nanping, in slow pace, emphasis on happiness and praise and are played by men and women, young and old linking arms. It will cycle one after another and not end until the highlight. Baima Tibetan does deserve the name "the town of singing and dancing" of which The most famous Heishui qu is "E Si Lao" that borrows the minor tone, "Bei Gong tone" and other essence in Pipa playing, forming its own characteristics. ${ }^{[1]}$ Enveloped songs, songs with string, are written in Tibetan with the tone of "Meng Jiang Nv". ${ }^{[2]}$ Enveloped songs are fluent and catchy and within 5 ranges. They are the songs that encourage people work hard. Antiphonal, ironic songs and tenso are folk songs sung in formal events. Folk songs sung in other situations are in a large number such as farewell songs, songs for guests and sleep songs. And Tibetan like folk songs sung after work to express emotions instead of words. 
Tibetan folk songs are the important part of its culture. They are inherited only by oral singing without word record and accompaniments. Tibetan folk songs include folk songs produced during working life and folk songs with its own characteristics influenced by other national cultures.

\section{Musical scale and debugging}

Tibetan folk songs which are based on pentatonic scale has three scale and heptachord scale and a few tetrochord. Tetrochord and three scale in this region are different from that in other regions, especially different from Kanfba folk songs favored pentatonic scale and Jiarong folk songs favored heptachord scale. Compared with Chinese traditional folk songs, pentatonic scale has its own features. Pentatonic scale of Tibetan folk songs can be divided into five standard tones applied pentatonic and the pentatonic formed by four standard tones and one partial tone or color tone. The famous "Dai Xi Ya Le" is the piece applied four standard tones and one color tone and "Wu Ke Lai He Cai Jin Shan" is a piece applied four standard tones and one partial tone. Applying five standard tones, Tibetan folk song in Nanping favor to use three or four standard tones and another one or two partial tones. That is totally different from that of Chinese traditional folk songs.

In terms of debugging, Yu is the most important but not the most common one in Tibetan folk songs in Nanping. The most common debugging are Gong and Hui. This is different from that of Tibetan folk songs in other regions. There is a certain amount of Jiao debugging of which its usage rate is bigger than that in other regions. On the whole, there is not much changes in debugging. Few alternation and transition of debugging appears in folk songs. But Gong and Hui are applied most, which implies the Tibetan folk song is charactered with masculine.

\section{Kernel scale}

The kernel scale of Tibetan singing and dancing in Nanping is composed of three and four scale. The melody basis of Tibetan folk songs is displayed through rhythm changes, scales alternation and scales decoration to show the logic aspect of the local folk songs. There are three forms of three-scale: scale A formed with second-third rank tone; scale B formed with second rank and third rank scale; scale $\mathrm{C}$ formed with second rank scale and third rank scale. There are two forms of four-scale: diverse kernel scale composed by adding one debugging on the basis of three-scale; the common and fixed scale which is the fixed term in Tibetan folk songs such as la-re-mi-sol and sol-do-re-mi. Although the use of this king four-scale is not so much as the former one, this is also one of the kernel scales in Tibetan folk songs.

The cultural characteristics and art basis of Tibetan culture can be showed through three-scale and four-scale in Tibetan singing and dancing in Nanping, especially the widespread application of three-scale.

\section{The ways of singing}

The ways of singing is close connected with lyrics. Generally, the confirmation of the way of singing is according to lyrics in order to reflect the rhythm features of Tibetan folk songs in Nanping. ${ }^{[3]}$ Meanwhile, the ways of singing is closely connected with Tibetan cultures, which shows the rich Tibetan culture. Briefly, the ways of singing of Tibetan folk songs in Nanping are three types: coloratura, Shuai-Qiang and drawl of which the most common one is the short drawl in drawl. Short drawl is to extent briefly and twistly. For example, "one word with more than one sounds" appears within four or five beats. The length of two to four beats is given priority in Tibetan folk songs in Nanping. The short drawl is applied in the end of the songs or the scale needs to be emphasized.

The modes of embellish cavity generally can be divided into glides, appoggiatura and Boeing. The former two modes are much more common, especially the slide down and the former appoggiatura. For example, “Zhu Qiang”, including a variety of modes of embellish cavity reflects not only the interesting and cultural feature of Tibetan folk songs in Nanping but also reflects 
reformed Tibetan dialect features which is impacted by dialect in Gansu. Enunciated short terms also show the character of dialect in Sichuan. The wide spread use of slide down is to reflect the blending cultures of Tibetan dialects. There are many slide down in Tibetan folk songs in Nanping especially in the pausing, which shows the character of dialect in Sichuan. The characters of applying modes of embellish cavity show that the folk songs and culture in this region are closely connected and Tibetan culture is integrated and developed through regional integration.

Padding syllables in Tibetan folk songs in Nanping are not as rich and active as that in Kangba. There are only simple function words to emphasize mood such as oh, god, ah, hey which are widely spread in Tibetan folk songs in undirected form. At the same time, among padding syllables, there are words and terms in Tibetan language like a na ye, suo lang ya zhuo na o which are not used much in Tibetan folk songs in Nanping. This is an envidence to prove that Tibetan folk songs in Nanping are different from that in other regions. Baima people has been living in Nanping for more than one thousand and five hundred years, and they created rich and integrated Tibetan culture which is showed in Tibetan folk songs. For example, the song "grandsons toast to grandpa" shows obvious Shanbei flavor. Its debugging mode is the same as that in Xintianyou and it is familiar to "Zou Xi Kou” in Shanxi from the section eight. ${ }^{[4]}$

\section{Features of turning methods}

The basic features of turning methods are soaring, falling slowly. In some folk songs, the highest tone appears in the very beginning of the song and it falls as serration. The turning methods of Tibetan folk songs are based on progressive supplement and complemented by big jump, but big jump is used frequently and even continuously. This reflects the obvious character, hale bright melody lines, which is different from other Tibetan folk songs.

Tibetan folk songs in Nanping apply progression layer by layer and circuitous development to make its range keep between eight to twelve ranks. There are few folk songs with over thirteen ranks. Methods of applying melody are repetition, overlapping embouchure and variation. There are some folk songs that apply the new melody by adaptable clipping or extending from existing ones. [5] Very few folk songs would adopt strict repetition because that would make the whole song stiff. With overlapping embouchure, the original melody will be kept and there are some changes in the repetition in order to realize the unity and changes of the entire melody. And overlapping embouchure generally utilize replacement and change of rhythm and increasing and decreasing of tone to reach the effort of the changes like "Rice in Summer" and "Thick Fog On Top of Mountain". At the end of melody, Tibetan folk songs end with the ending of the last third rank. Surely, it is common that it ends at the ending of second and forth rank. All in all, there are more songs ending at the downwards the that ending at the upwards. In addition, there are some Tibetan folk songs ending at partial or color scales. This is not so common in Chinese traditional folk songs and reflects the local feature of Tibetan folk songs. ${ }^{[6]}$

\section{Rhythm and form}

The tempos of Tibetan folk songs in Nanping are abundant. They are single tempo: 2/4 tempo, 3/4 tempo, 3/8 tempo and double tempo: $4 / 4$ tempo, 4/8 tempo, $6 / 8$ tempo and so on. 2/4 tempo is the most used one and is common in Tibetan folk songs as well as variable tempos such as $2 / 4+3 / 4$ tempo and 3/8+4/8 tempo. Most application of variation tempos cater to the characters of solo, long rhythm and personal feelings of Tibetan folk songs.

Regarding as types of songs, the type range of Tibetan folk songs is small and gives priority to one form within four phrases. And the form of two phrases is common and there are a few single two-type forms. The single three-type forms are rare. The phrase is comparatively neat and has similar length. This feature is another evidence to prove the difference from other Tibetan folk songs. Especially compared with Kangba, the relatively neat phrase is the local character. 


\section{Conclusion}

After one thousand years of prosperity and development, Tibetan singing and dancing in Nanping accumulate rich cultural connotation with great research value. For Tibetan folk songs are inherited orally and people's life style is changed by social economic development, Tibetan folk songs become assimilated and eroded. The relevant departments should intensify research and inheriting of Tibetan folk songs and encourage its prosperity and development. In addition to that, after Nanping was explored into a scenic area, Tibetan folk songs become an important part of the scene. The responsibility of modern people is not only to get to know it, but also to save and explore it. And how to save and protect the intangible cultural heritage is the duty of every art workers. This essay briefly introduces the characters of Tibetan folk songs from types, musical scales, debugging, features of turning methods, ways of singing, kernel scales, rhythm and types of songs in the hope of the attention from relevant art workers to encourage its prosperity and development.

\section{Acknowledgments}

This essay is the subject of Education Department of Sichuan Province, named The Arrangement and Research of Folk Songs in Nanping.

It is also the fruit of the innovation team "Research of Singing and Dancing in Qinba Mountain Area” Xihua Normal University.

\section{References}

[1]Ma Chengfu. Different Styles of Tibetan Folk Songs in Aba Prefecture in Sichuan[J]. Art research in Tibe, 2012(3): 35-40

[2]Zhao Yong. Brief Introduction of Folk Songs in Sichuan and Tibe[J]. Sichuan Drama, 2011(4):13-14

[3]Wei Xiaolan. The Research of Folk Melody of Jiarong Tibetan in Western and Northern Sichuan[J]. Music heaven, 2009(8):43-44

[4]Ma Chengfu, Xiu Hua. Splendid art-Analysis of Folk Song in Jiuzhaigou[J]. Journals of Aba Normal Higher Technical College, 2003(3):40-44

[5]Wei Xiaolan. Study on Musical Features of Tibetan Folk Songs in Kangba and Anduo in Sichuan[J]. Journals of Southwest University for Nationalities(Humanities and social science edition), 2010(4):23-26.

[6]Wei Xiaolan. Brief Analysis of Tibetan Folk Songs in Pingwu and Nanping in Sichuan[J]. Sichuan Drama, 2010(4):122-124 